\title{
The Royal College of General Practitioners revisited
}

\author{
Brian D Keighley
}

In its 40 years of existence the Royal College of General Practitioners has engendered emotional responses from many doctors in general practice. Those emotions have varied from complete antipathy to fervent support. During my own career in general practice I have made several criticisms of the college, sometimes objecting to individual policies, sometimes objecting to its apparent elitism, and sometimes objecting to the sheer impracticality of some of its more esoteric academic theories. However, very early on I decided that my own credibility would be enhanced by my becoming a member by examination rather than by bleating from the outside.

In 1980 I examined the aims and activities of the college. ${ }^{\prime}$ I suggested that for it to prosper it should investigate why there was so much active antipathy to it as an organisation from working general practitioners, and that it should be willing to change in response to valid criticism. Today, 13 years later, with a financial crisis, falling membership, and a failure to recruit new principals, it seems that some of my dire predictions have come to pass. But I take no satisfaction in this. Instead, I hope that by reviewing in a positive spirit the current state of the college at least some doctors might consider what the discipline stands to lose from a weakened organisation, especially in the light of service committee proceedings against its chairman of council, Dr Colin Waine, and his recent honourable, but tragic, resignation. Firstly, however, I believe that we should look at possible reasons why the college has become so unpopular with some general practitioners.

\section{Possible reasons for antipathy to college}

Since $1989-90$ the lives of all general practitioners have been blighted by the brutal imposition of a new contract. This compels doctors to work harder than ever before, often in activities of little scientific value, and introduces oppressive management control over a group of supposedly independent contractors. Evidence that such a contract is necessary because of lazy, incompetent general practitioners has never been produced. The Royal College of General Practitioners is tainted at least with a suspicion that it or some of its senior members at the time were involved in advising government in the construction of the contract and that some of those senior members gave the government covert advice and support over those difficult months.

Over the years the college has been accused of having a holier than thou attitude, and there is still a view that it sees itself as an elitist organisation that is, or should be, the fount of all knowledge and wisdom in connection with the discipline. The college is often seen as having inordinate power over matters of standards and training, yet until recently it could claim only a tiny proportion of practising general practitioners as members. Some doctors view the membership examination with suspicion because they think that the college's unwritten agenda is to establish it as an entrance ticket to general practice as a principal.

There are also the matters of assessment of vocational training and reaccreditation of existing principals, which are attracting increasing attention from both the profession and the government. ${ }^{2}$ Not surprisingly, perhaps, non-members resent the fact that a body in which they are not democratically represented is gaining power and influence over their careers.

\section{Compelling reasons for supporting college}

So much for a short list of matters that have produced antipathy. Now let us look at the other side of the equation and examine what the college has done to enhance the standing of the discipline. And at this point I state my belief that the time has come for general practice as a whole to support the college and wake up to what we stand to lose if it continues to decline in strength, membership, and influence.

Over the past decade general practice has attracted many of the brightest and best medical graduates. But it was not always so. I can remember when general practitioners were regarded with contempt by hospital staff. I can remember the disbelief on the faces of my medical teachers when I said that I was going to pursue general practice as a first choice. I can remember the job reference that said (quite rightly) that I was not suitable for a career in surgery, and the slightly pejorative comment that I would make a good general practitioner. I firmly believe that the main reasons for the change since I qualified 20 years ago are the academic activities of the college and their influence on professional standards.

The steady improvement in general practitioner training can be seen by tracing the increasingly high standards visited on regions by the Joint Committee on Postgraduate Training in General Practice (JCPTGP). It cannot be denied that the impetus for change has more often come from the college side of the joint committee than from the General Medical Services Committee (GMSC). There is now a vast library of publications on training, ranging from the almost unreadable The Future General Practitioner ${ }^{3}$ to the delightful reading of Roger Neighbour. ${ }^{45}$ Nearly all such publications have come from author members of the college and are respected internationally.

Despite the relative youth of our college it has commanded respect from the ancient royal colleges, which have conceded that much can be learnt from it in training and the inspection of standards. The Royal College of General Practitioners now has an established place in the royal college community, and when membership of government committees is sought it is often the only college that is offered a seat as of right.

General practice research has grown from the cottage industry approach of Will Pickles. With college support and expertise general practice research is now recognised as a most important source for health planning and needs assessment. Computing, publishing, assessment and examination techniques, standard setting, consultation skills, epidemiology, medical audit, therapeutics, practice organisation and management, community care planning, and many others are al subjects in which the college has raised the profile of general practice. Indeed, if the college had not been founded in 1952 many would now be trying to invent it.

The GMSC/LMC (local medical committee) structure has served general practice well for all of this century, defending its interests with tenacity and 
political skill. However, in today's consumerist and value for money society other skills and resources are required, which only the college can provide. For although the college may sometimes lack political skill, it always insists on an academic approach. The GMSC has no shortage of intellectual prowess in its own sphere of activity, but it needs a partner with an academic credibility to complement its own political skill. This credibility can come only from a body such as the Royal College of General Practitioners, which does not have to compromise its innovative ideas by knowing that it could not secure support in the annual conference of LMCs.

\section{Clarion call}

Plainly the time has come for the GMSC and the Royal College of General Practitioners to work together and present a united front to a government which demands more and more of us all but consistently fails to resource general practice with the means to carry out the job. Those with continuing suspicion of the college must realise that it is made up of general practitioners just like themselves, with the same contract, the same frustrations, and the same concern for patients. The pain of 1990 and all that the new contract brought must now be put behind us. Dr Ian Bogle, chairman of the GMSC, has opened a new debate on the future. ${ }^{6}$ If any of his ideas are to come to fruition the help and cooperation of the college will be needed.

Anyone who believes in general practice but who left the college because of disagreement with policy should now rejoin. All those new principals who sat the examination in order to get a job but never paid their subscription should pause and reflect. One reason that they enjoy the status of being a general practitioner principal is the activity of that very college that they have failed to join. I emphasise that I have never seen a time when professional unity was more essential.

I fear that a weakened Royal College of General Practitioners will weaken general practice as a whole. The only people who can restore the college to health are general practitioners. General practitioners must return to the fold, so that the college can recover morale, impetus, and finance for academic activity. This will not be achieved by cheering from the touchline.

1 Keighley BD. The RCGP: an inside view. BMY 1980;281:1506-7.

2 Irvine DH. General practice in the 1990 s:a personal view on future developments. Brf Gen Pract 1993;43:121-5.

3 Royal College of General Practitioners. The future general practitioner: learning and teaching. London: British Medical Joumal, 1972.

4 Neighbour R. The inner consultation. Lancaster: MTP Press, 1987.

5 Neighbour R. The inner apprentice. Lancaster: MTP Press, 1992.

6 Bogle I. General practice: which way forward? London: GMSC, 1993.

(Accepted 17 March 1993)

\section{Instructions to authors}

\section{General points}

- All material submitted for publication is assumed to be submitted exclusively to the $B M \mathcal{F}$ unless the contrary is stated and should conform to the uniform requirements for manuscripts submitted to biomedical journals (the Vancouver style; BMF 1991;302:338-41).

- All authors must give signed consent to publication

- The editor retains the customary right to style and if necessary shorten material accepted for publication.

- Type all manuscripts (including letters and obituaries) in double spacing with $5 \mathrm{~cm}$ margins.

- Number the pages.

Give the name and address of the author to whom correspondence and proofs should be sent.

- Do not use abbreviations.

Express all scientific measurements (except blood pressure) in SI units.

- Keep one copy of the manuscript for reference.

\section{Points specific to each section}

\section{PAPERS, GENERAL PRACTICE, EDUCATION \& DEBATE}

Papers report original research relevant to clinical medicine. They are usually up to 2000 words long with up to six tables or illustrations (short reports are up to 600 words with a maximum of one table or illustration and five references).

General Practice covers matters relevant to primary care.

Education \& Debate includes reports (up to 2000 words) on the organisation or assessment of medical work and on sociological aspects of medicine or the organisation, financing, and staffing of health services.

- Give the authors' names and initials and their address posts when they did the work.

- Papers and General Practice articles should conform to the conventional format of structured abstract (maximum 250 words), introduction, methods, results, discussion, and references. Education \& Debate articles should have an unstructured summary (maximum 150 words).

unstructured summary (maximum 150 words) for the This Week in $B M \mathcal{Y}$ page.

- Send three copies (if the paper is rejected these will not be Send three copies (if the paper is rejected these
returned; after three months they will be shredded).

returned; after three months they will be shredded). (not percentages alone).

- Any article may be submitted to outside peer review and assessment by the editorial committee as well as statistica assessment; this takes about eight weeks.

- Manuscripts are usually published within three months of the date of final acceptance.

LETTERS

- Should normally be a maximum of 400 words and five references.

Must be signed by all the authors.

- Only one copy should be sent.

- Only one copy should be sent. published in the journal.

published in the journal.
Authors do not receive proofs

Full instructions to authors appeared in the issue of 2 fanuary 1993, p 55
MEDICINE AND THE MEDIA

- Authors should discuss a proposed contribution with one of the editors before submitting it.

- Authors do not receive proofs

PERSONAL VIEW

- Should be a maximum of 1100 words

OBITUARIES

- Should normally be a maximum of 250 words.

- Should be received within three months of the person's death

- Authors should summarise the person's career in a separate paragraph and not repeat these details in the main text.

- Only one copy should be sent.

- Authors do not receive proofs.

Tables

Should be on separate sheets of paper from the text.

- Should not duplicate information given in the text of the article.

- Whenever possible, when relevant, numbers of patients or Wubjects studied should be given (not percentages alone).

- If a table has been published previously written consent to republication must be obtained from the copyright holder (usually the publisher) and the author(s)

Figures

- Should be used only when data cannot be expressed clearly in any other way.

Should not duplicate information given in the text of the article.

- The numerical data on which graphs, scattergrams, and histograms are based should be supplied.

- Whenever possible, when relevant, numbers of patients or subjects studied should be given (not percentages alone)

- Legends should be on separate sheets of paper from the text.

- If a figure has been published previously written consent to republication must be obtained from the copyright holder (usually the publisher) and the author(s).

LINE DRAWINGS

- Should be presented clearly to aid redrawing.

FIGURES THAT ARE NOT LINE DRAWINGS

- Should usually be glossy prints.

- Should be no larger than $30 \times 21 \mathrm{~cm}$ (A4).

- Important areas should be indicated on an overlay.

- The top should be marked on the back.

- Photomicrographs should include an internal scale marker.

- Labelling should be on copies, not on the prints.

- Patients shown in photographs should have their identity concealed or give written consent to publication (BMF concealed or give
1991;302:1168).

Staining techniques for photomicrographs should be stated in the legend. 